\title{
Covid-19 vaccines production and societal immunization under the serendipity-mindsponge- 3D knowledge management theory and conceptual framework
}

\author{
Quan-Hoang Vuong ${ }^{1 凶}$, Tam-Tri Le ${ }^{1,2}$, Viet-Phuong La (i) ${ }^{1}$, \\ Huyen Thanh Thanh Nguyen (10 ${ }^{1}$, Manh-Toan Ho (D) ${ }^{1}$, Quy Van Khuc (B) ${ }^{3}$ \& \\ Minh-Hoang Nguyen (i) ${ }^{1,2 凶}$
}

Since the outbreak of the Coronavirus disease 2019 (Covid-19), tremendous efforts have been made by scientists, health professionals, business people, politicians, and laypeople around the world. Covid-19 vaccines are one of the most crucial innovations that help fight against the virus. This paper attempts to revisit the Covid-19 vaccines production process by employing the serendipity-mindsponge-3D creativity management theory. Vaccine production can be considered an information process and classified into three main stages. The first stage involved the processes of absorbing information (e.g., digital data and open science) and rejecting unhelpful information (e.g., misinformation and fake news) for effectively acquiring useful insights. Useful insights were later employed by experts, enterprises, governments, and international organizations through interdisciplinary coordinated efforts for developing vaccines within a short period. Finally, the appearance of multiple types of vaccines enabled more strategic options for vaccine distribution and administration. Findings from this vaccine creativity management process could be used as critical lessons for further improvements of vaccination programs.

\footnotetext{
${ }^{1}$ Centre for Interdisciplinary Social Research, Phenikaa University, Hanoi 100803, Vietnam. ${ }^{2}$ AISDL, Vuong \& Associates, Dong Da Hanoi 100000, Vietnam. ${ }^{3}$ Center for Economic Development Studies and Faculty of Political Economy, VNU University of Economics and Business, Vietnam National University,

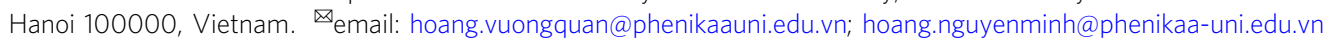




\section{Introduction}

ince February 2020, the world has gone through unprecedented times facing the existential threat caused by Covid19. Compared to other public health crises from 2008, Covid-19 has significantly stronger negative impacts on the global economy, among countless other social aspects (Schell et al., 2020). A century after the influenza pandemic back in 1918-1920 (a.k.a. Spanish flu), humanity has been facing another fatal pandemic again.

During the Covid-19 pandemic, humanity has benefited from numerous epidemiological, public health, economic and sociocultural, political innovations on a global scale. Tremendous efforts have been made by scientists, health professionals, business people, politicians, and laypeople around the world. One of the most critical innovations is the Covid-19 vaccines, which arrived in late 2020. They have been expected to help prevent the spread of the SARS-CoV-2 variants. The birth of these vaccinesof which, Sputnik V, Pfizer-BioNTech BNT162b2, Moderna mRNA-1273, AstraZeneca-Oxford AZD1222, CoronaVac have been approved and used widely-has involved numerous actors from the most scientifically and technologically advanced countries such as the United States (US), the United Kingdoms (UK), the European Union, Russia, China, to name just a few.

By June 25, 2021, more than 2.88 billion doses have been produced and distributed across the globe in an urgent effort to fight Covid-19. About 1.77 billion people in 213 countries have been vaccinated at least one dose (Mathieu et al., 2021). It is helpful to conduct an in-depth conceptual investigation into the process of producing, administrating, and distributing Covid-19 vaccines. While there are concerns about the high speed of Covid19 vaccine development, the process was not recklessly rushed.

The vaccine innovations have not come out of the blue but through effective and efficient interdisciplinary-coordinated efforts and investments (both medical and non-medical) of many individuals and institutions. This paper is dedicated to revisiting those innovation-making processes using the $3 \mathrm{D}$ creativity management (or knowledge management) theory (Vuong and Napier, 2014) to provide insights and lessons from this global fight against the Covid-19 pandemic. In addition, we employed a creativity management theory on the particular topic of vaccine development because we believe it would help navigate, connect information, and clarify insights better within an overwhelming ocean of Covid-19 related information. Insights from this study are also expected to facilitate the subsequent production, administration, and distribution of modified vaccines and vaccination campaigns.

\section{Information processes throughout the Covid-19 pandemic}

The $3 \mathrm{D}$ creativity management theory is a conceptual framework that explains how creativity and innovations are made through information processes. The framework is appropriate and practicable on the individual, organizational, and national levels within different contexts (Dang et al., 2013; Q.-H. Vuong, 2016a, 2016b; Vuong and Napier, 2015; Nguyen et al., 2021; Vuong et al., 2021; Vuong and Napier, 2013). This paper employed it to explain Covid19 vaccine development on a global scale. Conceptually, the 3D framework has three major blocks: (1) the information absorbing and filtering block, (2) the creativity processing block, and (3) the innovation outcome block. Although each block has particular functions and operations, they are seamlessly and closely connected. Figure 1 demonstrates how the vaccines were made through three major blocks of the 3D framework. In each block, some notable corresponding events and activities are also indicated.

Digital data, infodemic, misinformation, and fake news. In late December 2019, cases of pneumonia with an unknown cause were epidemiologically linked to a seafood wholesale market in Wuhan, China (Zhu et al., 2020). The unknown agent was later identified as betacoronavirus SARS-CoV-2 or coronavirus disease 2019 (Covid-19), which has a close sequence identity to severe acute respiratory syndrome coronavirus (SARS-CoV) - the causative agent for the 2002-2004 SARS outbreak (Zhou et al., 2020). Due to the high transmission rate of Covid-19, it had caused subsequent outbreaks all over the world not long after the detection in Wuhan ( $\mathrm{Hu}$ et al., 2021). On January 30, 2020, the WHO Director-General declared the novel coronavirus outbreak a Public Health Emergency of International Concern (PHEIC) (Organization W. H., 2020).

In the very early stage of the pandemic, facing critical problems without sufficient effective information input, many governments acted reluctantly (or almost ignored) when receiving news and warnings from WHO about the risk of Covid-19. Parts of the cause were argued to be communication concerns of the term PHEIC (Maxmen, 2021). Given that Covid-19 is highly transmissive and there was no effective vaccine and therapy for treating Covid-19, the main strategies of governments at the time were coordinated containment and mitigation strategies, like surveillance, testing, contact tracing, and strict quarantine (Whitelaw et al., 2020).

In a high-entropy setting where the virus transmission network was nearly "invisible", and the world activities were still occurring at high speed, implementing containment and mitigation strategies was a significant challenge for governments worldwide. Therefore, governments had to monitor, control, and manage the multiplex and tremendous amount of information to develop appropriate policy responses or strategies. This process is similar to the initial step of the 3D framework: evaluating, comparing, and connecting information to determine whether to absorb and generate insights based on the given information or discard them.

To effectively monitor, control, and manage information, digital technology (e.g., big data and artificial intelligence) had been integrated into the governments' pandemic preparedness and responses strategies: (1) contact tracking, (2) quarantine and self-isolation, (3) screening for infection, (4) clinical management, and (5) planning and tracking (Whitelaw et al., 2020). Chinese authorities used mobile phones, mobile payment applications, and social media to track the movement of people who had visited the infected areas (Wu et al., 2020). The data collected from thermometers at workplaces, schools, public transport in Singapore was tracked and employed to detect potential clusters of infection for initiating testing (Samantha, 2020). A smartwatch application was launched in Germany to collect pulse, temperature, sleep pattern data, which were later used by the authorities to estimate the likelihood of a Covid-19 outbreak (Douglas, 2020). International travelers in Australia were forced to wear tracking devices during their self-quarantines at hotels (Pannett and Cherney, 2020). Virtual care platforms were introduced in Australia, Canada, and the US to deliver remote care to patients due to the rising burden on healthcare facilities (Caretaker, 2020; MacLeod, 2020; McCormick and Shah, 2020).

Even though digital technologies offered platforms, tools, and applications to monitor, control, and manage information of infected people, they also provided a breeding ground for fake news, myths, and conspiracy theories. The World Health Organization (WHO) has described the rampant misinformation and disinformation as a "massive infodemic" (Fleming, 2020). Misinformation and disinformation have become even more dangerous in the pandemic since they directly impact life and death outcomes. For example, the popular myth that consumption of highly concentrated alcohol could kill the virus had resulted in around 800 mortalities, almost 6000 people being hospitalized 


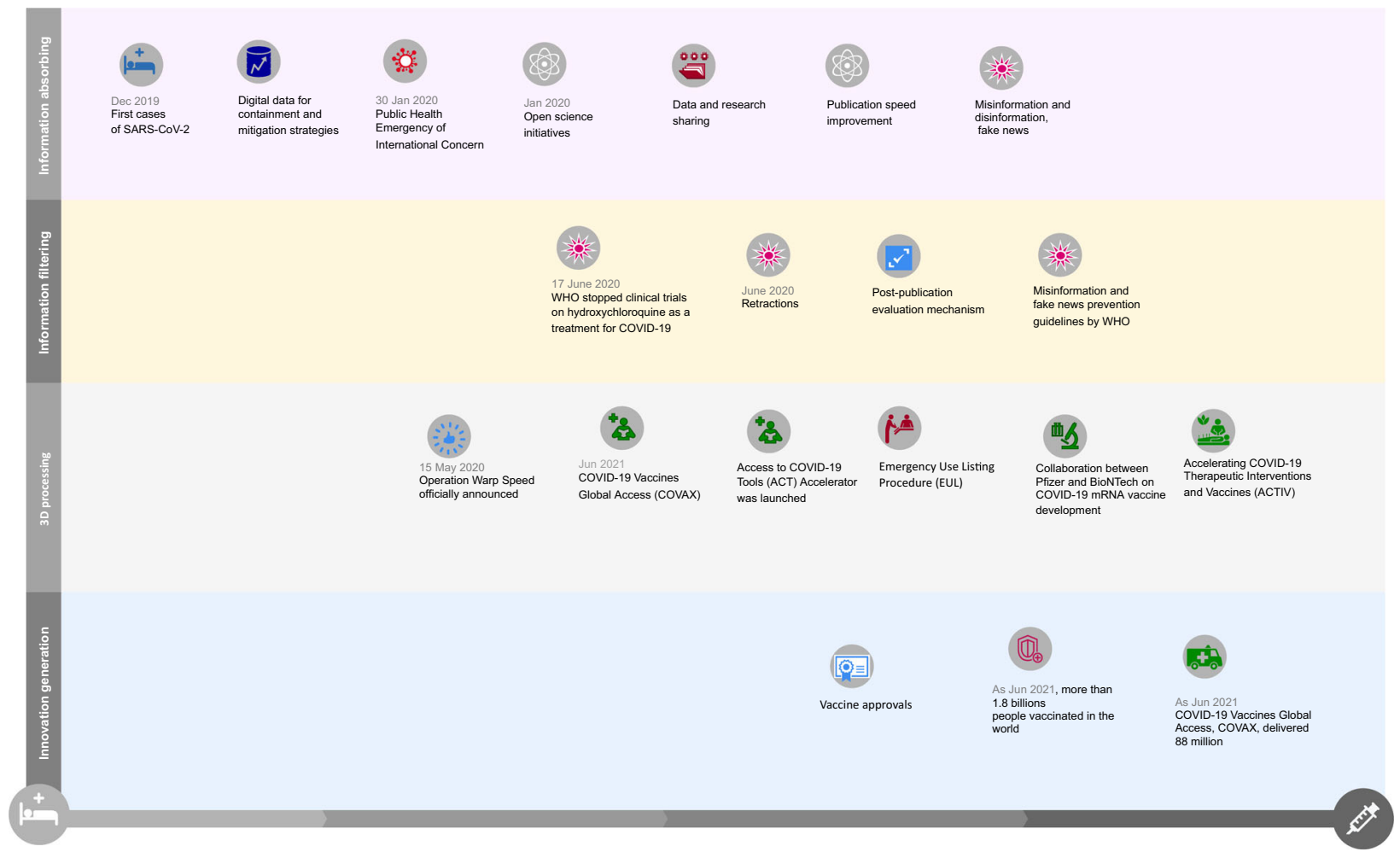

Fig. 1 The overall creativity process of making Covid-19 vaccines.

(Islam et al., 2020). Some people believed in the conspiracy theory that Covid-19 was spread by $5 \mathrm{G}$ wireless towers, resulting in around 80 harassment incidents, 30 acts of arson and vandalism, and even burning cell towers (Satariano and Alba, 2020). Covid19-related information was also used as a weapon by online hate communities, such as neo-Nazis, fascists, white supremacists, antiSemites, Islamophobes, cis-gender male supremacists, to push ideas of malicious intents (Velásquez et al., 2021).

The misinformation was also intensified by politicians' inappropriate speech and decisions, which created more burdens for the information filtering process (or information management process). From February to October 2020, former US President Donald Trump publicly spoke about Covid-19 in an overly hopeful manner, repeatedly stating that the virus would soon "disappear", "this is like flu", or "it's very mild" (Tollefson, 2020; Wolfe and Dale, 2020). At the White House coronavirus taskforce briefing on April 23, 2020, President Trump also suggested the idea of injecting disinfectant as a form of treatment, which caused intense disapproval among healthcare professionals as well as common people not only in the US but around the globe (Smith, 2020). Researchers said that President Jair Bolsonaro's administration was publicly ignoring them in Brazil. President Bolsonaro also referred to Covid-19 as a "little flu" and undermined vaccines' value by warning that Covid-19 vaccines could turn people into crocodiles (France24, 2020; Taylor, 2021). The situation was so grave that many leading scientific journals, such as Nature, Science, and The Lancet, had to increasingly cover politics to prevent some political leaders' misunderstanding, misusing, or even suppressing Covid-19 related research (Jeffrey, 2020; Lancet, 2020; Nature, 2020).

The effectiveness of vaccine distribution and injection heavily depends on public perception of the vaccines. Misinformation about Covid-19 could lead to challenges to implementing public health strategies and vaccination. Thus, the information filtering on collective levels (e.g., the fight against misinformation) affects the common public's knowledge and the whole endeavor of the scientific community and governments. A study using a dataset of 5000 people in five countries (Ireland, Spain, Mexico, the US, and the UK) during April and May 2020 found that misinformation was negatively associated with compliance to public health guidance, willingness to get vaccinated, and recommend the vaccine to friends and families (Roozenbeek et al., 2020). Vaccine conspiracies targeting vaccine funders and health directors might also result in a decline of public trust in vaccine development efforts and the subsequent deployment of vaccines campaigns (Haroon, 2020; Stankiewicz, 2020).

The WHO released guidance on April 8, 2020, with 50 key actions to help individuals, community leaders, governments, and private sectors curb the increasingly expanding infodemic (WHO, 2020a). The WHO has also been working with major social media platforms and digital companies, like Facebook, Twitter, LinkedIn, TikTok, Twitch, Snapchat, Pinterest, Google, Viber, WhatsApp and YouTube, making official sources about Covid-19 appear first (WHO, n.d.). Countries around the globe also took action and had their own strategies to fight fake news, misinformation, and disinformation (Fleming, 2020; La et al., 2020). Thanks to these efforts, Covid-19-related content on Twitter was found to shift toward more credible sources in the later phase of the pandemic (Gallotti et al., 2020). Upon collecting data from Gen Z and Millennials from late October 2020 to early January 2021, WHO also found that more than half of them are well-aware of Covid-19 fake news, and about $44 \%$ of them said that the Covid-19-related information they are likely to post on social media is scientific content (WHO, 2021).

Open science, preprints, and retractions. Although the containment and mitigations effectively flatten the infection and mortality curves, they are not sustainable solutions because a globalized world could not be disconnected for so long. The vaccine was seen as the imperative solution to stop the pandemic and revise the global economy by establishing sufficient herd 
immunity (Graham, 2020). At the beginning of the Covid-19 pandemic, the idea of relying on vaccination to combat Covid-19 was quite pessimistic because it was initially believed to probably take 10 to 15 years to sufficiently develop a vaccine in normal situations (Jocelyn, 2020). Until 2020, the fastest vaccine made was the mump vaccine after a four-year process. Another concern about vaccine development was its safety (Graham, 2020).

Fortunately, in reality, we have successfully created not only one but many types of Covid-19 vaccine in less than a year. Such success is believed to be attributed to scientific initiatives and efforts during the pandemic and earlier scientific activities, like utilizing highly adaptable vaccine platforms (e.g., RNA) and adapting structural biology tools to design agents (e.g., immunogens). But, how was the vaccine-making process shortened from a decade to less than a year while not compromising safety?

The 'miracle' of Covid-19 vaccine creation can be wellexplained by the $3 \mathrm{D}$ creativity framework. According to the $3 \mathrm{D}$ framework, the input for generating innovations is information. Useful insights - the prerequisites of innovations-are the outcomes of the 'creative quantum' (or information filter) after evaluating, connecting, comparing, and imagining based on information input. Therefore, to increase the probability of generating innovations, one has to increase the number of useful insights, which can be achieved by increasing the amount of information processed and the processing speed.

Open science-making scientific data and information swiftly available and shared (Forni et al., 2021; Zastrow, 2020)—was a typical example of increasing the amount of information. Since the first genome sequence of the SARS-CoV-2 was shared on GISAID and Nextstrain in early January, the number of shared data on these platforms has increased rapidly (Shu and McCauley, 2017; Zastrow, 2020). Also, in January 2020, a statement titled "Sharing research data and findings relevant to the novel coronavirus (Covid-19) outbreak" was signed by 117 organizations, including journals, publishers, funding bodies, and centers for disease prevention. Some notable practices of the initiative are removing paywalls to scientific documents and making use of preprint servers (Wellcome, 2020).

Two months later, the initial commitment was reinforced by the Public Health Emergency Covid-19 Initiative launched by 12 countries (Wellcome, 2020). After that, scientists, lawyers, and technology companies-like Intel, Facebook, Amazon, IBM, SandiaNational Laboratories, Hewlett Packard, Microsoft, Uber, Open Knowledge Foundation, the Massachusetts Institute of Technology, and AT\&T - continued to launch the Open COVID Pledge (Open COVID Pledge, 2020), calling individuals to make their intellectual property available and free of charge to help fight the Covid-19 pandemic. Furthermore, many other remarkable initiatives and programs offer resources for scientific research, namely: CORD-19 (CORD-19, 2020), MOBS Lab, MIDAS, ELIXIR, COVID-19 Data Portal, Covid-19 High-Performance Computing Consortium, etc. (Wellcome, 2020).

Besides sharing research data, tools, and findings, rapid dissemination of research results for open dialog was another prominent way of facilitating the insight generation process (Vuong, 2017). It was found that Covid-19 related preprints on bioRxiv and medRxiv were accessed, cited, and shared more than those not related to Covid-19 (Fraser et al., 2021). Majumder and Mandl (2020) suggested that preprints might be driving the Covid-19 discourse due to its speed of information dissemination. For increasing the disseminating speed of research findings, peerreviewed journals also prioritized processing articles involving Covid-19. An analysis of 14 journals, mainly in virology, indicated that the average number of days between submission and publications during the pandemic had declined almost a half compared to that before the pandemic (Kwon, 2020).
The outcomes of increasing the amount of information and processing speed were impressive. It was estimated that more than 200,000 Covid-19 related journal articles and preprints had been published by early December. Most research in the early period of the pandemic (from January to April) modeled the spread of disease, people hospitalized, and diagnostic and testing outcomes. Later, research topics became more diverse, with a larger number of studies about public health, diagnostics, mental health, etc. (Else, 2020).

However, inherent risks were also the by-products of the innovation-creating process, especially in the high-entropy setting (e.g., the early stage of the pandemic). One of the most significant risks was disseminating inaccurate information and poor-quality research through preprint posting practices (Martins et al., 2020) and rapid scientific publication among medical journals (Horbach, 2020; Khatter et al., 2021). One notable example regarding the bad influence of low-quality preprints was the report about the incubation period for Covid-19 by the national newspaper in Singapore (The Straits Times) on February 27, 2020, based on the incorrect interpretations of a non-peer-reviewed preprint (Bagdasarian et al. 2020). Months later, the retraction of publications from two prestigious medical journals on June 4, 2020, The Lancet (Mehra et al., 2020) and The New England Journal of Medicine (Mehra et al., 2020), reinforced the critics of poor-quality research due to rapid scientific publication. For instance, the retraction of a paper about hydroxychloroquine's impact on Covid-19 from The Lancet caused strong reactions in the scientific communities and across the public (Ledford and Van Noorden, 2020). It is also worth noting that WHO stopped clinical trials on hydroxychloroquine as a treatment for Covid-19 on June 17, 2020, due to their ineffectiveness (WHO, 2020b).

In the $3 \mathrm{D}$ process, the 'creative quantum' also has the function of discarding 'garbage' or waning information, apart from generating insights. It was similar in the scientific production process. The preprint servers' moderators and journals' editors imposed additional quality control methods to improve the credibility of information and insights from preprint systems and rapid scientific publications (Bauchner et al., 2020; Kwon, 2020). In particular, papers submitted to BioRxiv and medRxiv have to undergo a two-tiered vetting process: in-house staff screening and volunteer academics or subject specialists' examinations (Kwon, 2020). For ensuring the credibility of research findings while maintaining the rapid publication process, journals, such as JAMA (The Journal of the American Medical Association), had relied on their abundance of editorial resources and postpublication feedback system (e.g., online comment platform) (Bauchner et al., 2020).

The Retraction Watch initiative by the Center for Scientific Integrity also joined hands to vet the research quality of published articles. They created a separate site for tracking the retracted Covid-19 papers. By now, 139 papers have been retracted, according to Retraction Watch (2021). Still, a retraction reporting mechanism is required to clarify "who initiated it; the cause (such as severe errors, plagiarism or fraudulent practices); whether there is consensus between editors and authors about it; and whether post-publication review (such as comments on PubPeer) was involved" (Vuong, 2020). Furthermore, the sole efforts of organizations, publishers, and journals are never enough to ensure research integrity. Striving to create high-quality studies is also the responsibility of authors. They must be honest by not fabricating, falsifying, and misrepresenting data (Bauchner et al.,2018).

\section{Coordinated efforts through the 3D framework}

When the world became determined to produce vaccines for Covid-19, the $3 \mathrm{D}$ process of creativity was the creative production 


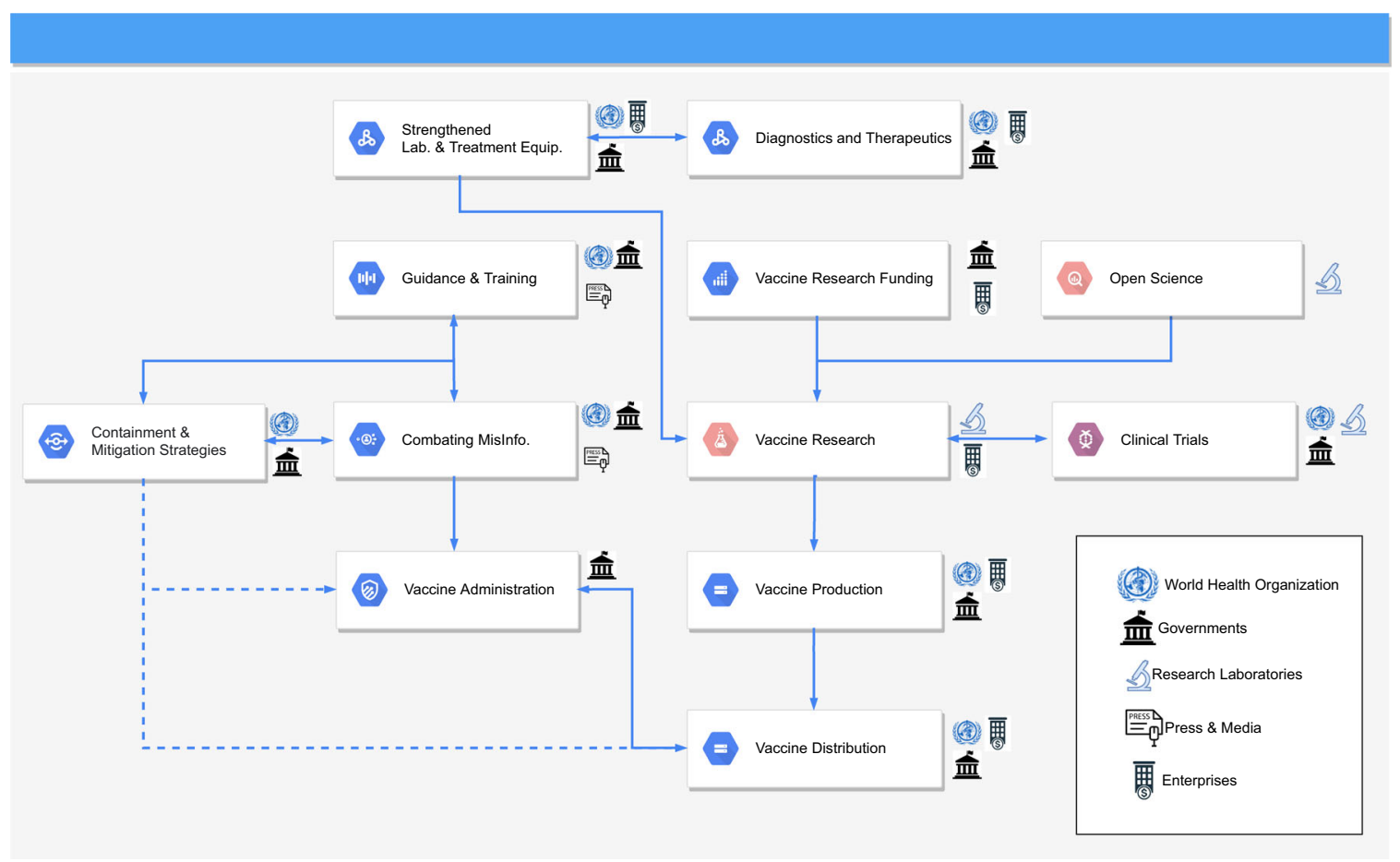

Fig. 2 The 3D process of vaccine development and production.

and management of the vaccine development process. The information inputs were more organized at this stage, directions were clearer, and predictions were more accurate. The governments, WHO, pharmaceutical manufacturers, scientific communities, trial participants, media, etc., all contributed to creating an ecosystem of information with a common purpose. Those interdisciplinary-coordinated efforts are presented in Fig. 2. It should be noted that the orange icon represents 'within discipline' efforts, the blue icon represents 'out-of-discipline' efforts, and the purple icon represents both.

Expertise. The 3D process's aspect of 'within-discipline' can be observed because all the top institutes and organizations directly carrying out the vaccine development and production process have the human resources (e.g., researchers and managers) who can be considered among the best within the discipline of making the vaccine. This can be viewed as the optimal knowledge and insights necessary for the creative process.

The first Covid- 19 vaccine that completed phase 3 in the world, Pfizer/BioNTech BNT162b2, is the product of Project Lightspeed (BioNTech) administered by the corresponding companies, research institutes, and governmental bodies. It was the combination of the mRNA-based technology of BioNTech (Germany) and Pfizer's global vaccine development capacities (US). The collaboration between Pfizer and BioNTech on Covid19 mRNA vaccine development started from March 2020 (also with Fosun Pharma-China), accelerating human trials for multiple vaccine candidates in May 2020. Pfizer's Chief Scientific Officer and President Mikael Dolsten stated that this could be considered an 'unprecedented collaboration across the innovation ecosystem' (Pfizer, 2020b). With the supply chain including 40 Pfizer-own sites and more than 200 global suppliers, in November 2020, they were projected to produce 1.3 billion vaccine doses in 2021 (Pfizer, 2020a).

On April 17, 2020, the NIH announced the Accelerating Covid-19 Therapeutic Interventions and Vaccines (ACTIV) public-private partnership in the US. The ACTIV initiative focuses on four areas (pre-clinical, therapeutics, clinical trial capacity, and vaccines), each of which was led by a group of senior scientists (National Institutes of Health). The National Institute of Allergy and Infectious Diseases (NIAID) of the NIH carried out many large-scale clinical research studies with phase 3 trials on different Covid-19 vaccine candidates in 2020 alongside other trials for treatment (National Institutes of Health).

Additionally, in a global crisis, the issue of expertise was also considered on international levels. On October 2, 2020, CEPI announced establishing a global network of laboratories to compare immunological responses of Covid-19 vaccines (CEPI, 2020; Kumar et al., 2021). All Covid-19 vaccine developers in the world can utilize the network to quickly and accurately assess candidates. On April 16, 2021, WHO decided to establish a vaccine technology transfer hub to help increase the capacity of low-income and middle-income countries in producing Covid-19 vaccines, which includes providing technology packages and appropriate training (World Health Organization, 2021c). The transfer hub initially focused on mRNA vaccine technologies but would expand further in the future. In June 2021, the first mRNA vaccine technology transfer hub was established in South Africa (World Health Organization, 2021f).

Collaborations. The 3D process's aspect of 'out-of-discipline' can be observed through the huge network of partnerships and engagement among various stakeholders and participating organizations across multiple fields. Developing and producing vaccines in times of crisis requires global interdisciplinary coordination, such as biomedical research (e.g., laboratories), manufacture (e.g., pharmaceutical companies), management (e.g., international organizations, governments, and public healthcare systems).

On April 24, 2020, WHO, European Commission, France, and the Bill \& Melinda Gates Foundation co-hosted the Access to Covid-19 Tools (ACT) Accelerator-a global-scale collaboration framework for rapid research and development as well as resources mobilization (World Health Organization). Many large 
global organizations participated in this partnership, including the World Health Organization (WHO), the Coalition for Epidemic Preparedness Innovations (CEPI), Gavi, the Vaccine Alliance, the Global Fund to Fight AIDS, Tuberculosis, and Malaria (Global Fund), Unitaid, the Foundation for Innovative New Diagnostics (FIND), the Wellcome Trust, the World Bank Group, the Bill \& Melinda Gates Foundation, and the United Nations Children's Fund (UNICEF). Within the first 12 months of operation, the ACT Accelerator mobilized the total funding of 14.1 billion USD from both the public and private sectors (World Health Organization, 2021a).

The ACT Accelerator has three pillars of Diagnostics, Therapeutics, Vaccine, supported by the Health Systems Connector and the country allocation and access workstream. Without global collaboration, if governments uncoordinatedly try to supply their populations by signing agreements with pharmaceutical manufacturers (the so-called "vaccine nationalism"), it may result in a global GDP loss of up to $\$ 1.2$ trillion a year (Hafner et al., 2020). The vaccine pillar-Covid-19 Vaccines Global Access (COVAX)-accelerates the development and manufacture of vaccines, research agenda for new variants, and ensures equitable global distribution. COVAX invested 1.2 billion USD in the vaccine development process (World Health Organization, 2021a).

In the US, on May 15, 2020, the Trump Administration announced an operation for facilitating and accelerating the development, manufacturing, and distribution of Covid-19 vaccines, therapeutics, and diagnostics with an initial budget of 10 billion USD (U.S. Department of Defense, 2020). This was originally known as Operation Warp Speed. The operation is a joint effort by the Department of Defense (DOD) and the Department of Health and Human Services (HHS); including the familiar US organizations: the Centers for Disease Control and Prevention (CDC) and the Food and Drug Administration (FDA), as well as the National Institute of Health (NIH) and the Biomedical Advanced Research and Development Authority (BARDA) (U.S. Department of Defense). The cooperation also extended to private firms and other federal agencies, including the Department of Agriculture, the Department of Energy, and the Department of Veterans Affairs (National Institutes of Health, 2020).

It is also worth noting that the battle against misinformation at this stage expanded more on the front of information about Covid-19 vaccines. For example, there were conspiracy theories spreading on social media platforms about microchips in vaccines, genetic modifications, and pharmaceutical profits (Hotez et al., 2021; Ullah et al., 2021). Thus, the future success of the vaccine development and production process continued to rely on the efforts from the governments and media to prevent misinformation.

Protocols and authorizations. The 3D process' aspect of the 'disciplined process' can be observed through the strict protocols to ensure the vaccines' safety and efficacy. This includes every step of the development and production process, from pre-clinical, to clinical trials, manufacture, and administration.

WHO has been rigorously tracked detailed information about vaccine candidates in pre-clinical and clinical development to monitor their safety and efficacy (World Health Organization, 2021b). As of June 6, 2021, there were 184 vaccines in pre-clinical development and 104 in clinical development. Among those in clinical trial phases, protein subunit type accounts for $32 \%$ of candidates, followed by non-replicating viral vector type, which accounts for $15 \%$. Their data set includes links to reports for each phase of trials and phase 3 endpoints per protocol for each candidate. The WHO uses the Emergency Use Listing Procedure (EUL) (World Health Organization) to approve the emergency use of vaccines. As of May 18, 2021, WHO has approved the emergency use for the following vaccines: AstraZeneca-Oxford, Pfizer-BioNTech, Sinopharm-BBIBP-CorV, Moderna, Sinovac, and Johnson \& Johnson (World Health Organization, 2021d).

Even though it was desirable to speed up the vaccine development process as much as possible, maintaining a highly disciplined system helped prevent risky compromises, such as the vaccine evaluation processes in Operation Warp Speed (National Institutes of Health, 2020; U.S. Government Accountability Office, 2021). On December 2, 2020, the UK became the first to issue emergency use authorization (EUA) to Pfizer-BioNTech BNT162b2 vaccine (Ledford et al., 2020). On December 11, 2020, the FDA of the US also issued EUA to the Pfizer-BioNTech Covid-19 vaccine (U.S. Food and Drug Administration, 2021).

Here, we can also see that creativity must satisfy both conditions of originality (new vaccine development and production methods) and effectiveness (safe vaccines with sufficient efficacy). Cooperation among component parties is crucial in the process (e.g., labs and research institutes working on biomedical research, the governing bodies setting standards and supervising, the pharmaceutical firms preparing for mass-production, etc.)

Through the multifactor process of vaccine development and production, we can see that the three aspects of $3 \mathrm{D}$ are deeply intertwined like a trefoil knot and cannot be separated. Additionally, we can derive two important points. Firstly, the result of this creative process-the 'a-ha!' moment of successfully creating an effective vaccine-is not serendipitous (although it needs many serendipities as inputs) (Napier and Hoang Vuong, 2013). Rather, it is a product of a disciplined process utilizing high-quality sources of information and insights (from out-ofdiscipline and within-discipline experts). Secondly, this process of creativity is directional and can be sped up. By providing the optimal conditions (as good as possible working environment) for the creative process, we can increase the probability of radically innovative products being born. Indeed, it is not likely that simply by random chance, humans would be able to produce vaccines that were formerly thought to take about ten years in less than a year.

\section{The vaccine arrivals in the world}

The vaccine rollout does not only prevent public health loss due to Covid-19 but is also prospected to provide substantial economic values. According to Sandmann et al. (2021), the introduction of vaccines would considerably reduce the economic loss due to Covid-19 of the UK in the next 10 years. However, small outbreaks could continue to emerge (Sandmann et al., 2021). The introduction of the Covid-19 vaccine is crucial for the economic recovery that the International Monetary Fund (IMF) Managing Director called it the 'most important economic policy of 2021 and urged to get $40 \%$ of the global population vaccinated by the end of this year, and around $60 \%$ by June 2022 (Amaro, 2021).

After the release of vaccines, many countries worldwide have rapidly deployed vaccination campaigns (see Table 1 ). The top five countries that had the highest number of vaccine doses administered per 100 people until June 28, 2021, were: Israel (123.75), the UK (113.48), the US (96.68), Canada (94.05), and Germany (86.20) (Mathieu et al., 2021). As a result, some of them also belong to the top five countries with the greatest percentage of fully vaccinated population: Israel $(59.61 \%)$, the UK (48\%), the US (45.76\%), Germany (35.13\%), and Italy (29.45\%) (Mathieu et al., 2021).

Among nationwide vaccination campaigns that have been conducted, Israel's vaccine rollout could be considered the fastest. 


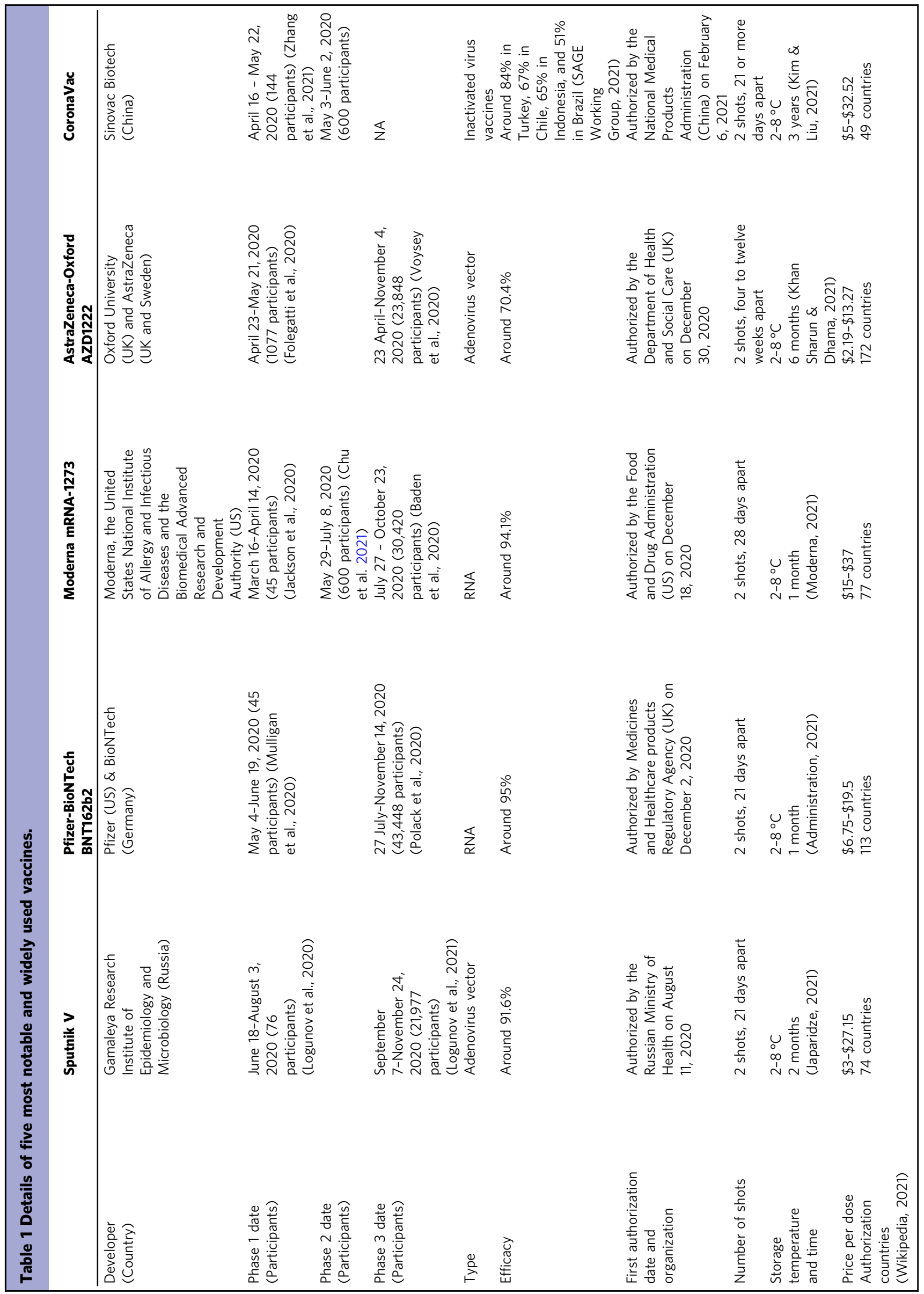


Three months after the rollout began (from December 19 to March 19, 2021), $60 \%$ of the population had been vaccinated with at least one dose (Mathieu et al., 2021). An observational study in Israel found that two doses of Pfizer-BioNTech BNT162b2 were highly effective in preventing SARS-CoV-2 infections and Covid-19 related hospitalizations, severe diseases, and death across all age groups (Haas et al., 2021). Other countries deploying vaccination campaigns also witnessed a decrease in confirmed cases and deaths. An exemplary case is the US. Since its mass campaign on December 14, 2020, the 7-day rolling average of daily new confirmed cases and deaths per million people has declined from 655.45 and 7.75 to 36.03 and 0.87 (as of June 27, 2021) (Mathieu et al., 2021).

Russia launched the Sputnik V vaccine on August 11, 2020, followed by controversies as the world digested the new information. While the developers touted the safety and efficacy of Sputnik V, others expressed concerns about the early approval of the vaccine from the Russian government, as it did not only involve health aspects but also how the geopolitics pressure might cause other countries to cut corners in the development process as well (Al Jazeera, 2020; Balakrishnan, 2020). Although still skeptical in the first half of 2021, the global perception has shifted toward more neutral or even positive responses (DW, 2021a; Jones and Roy, 2021). Russia's President Vladimir Putin was vaccinated with Sputnik V in March 2021, saying that the vaccine was "the best in the world". Although domestic vaccine supply was considered relatively more available compared to other European countries' situations, the national vaccination campaign in Russia faced trust issues such as logistics in rural areas and misinformation, leading to low willingness (DW, 2021b). As of June 2021, Russia has administered more than 38 million doses, with a weekly average of more than 450 thousand doses (Reuters). As of December 2021, Sputnik V was still under evaluation for emergency use authorization by the WHO. Still, two EU member states (Hungary and Slovakia) had rolled out the vaccine quite early (Euronews, 2021).

The Covid-19 Chinese vaccine BBIBP-CorV (by Sinopharm) and CoronaVac (by Sinovac Biotech) are late-comers compared to other popular names such as Pfizer-BioNTech, AstraZenecaOxford, or Sputnik V. Due to their relatively lower and varied efficacy rates, the vaccine did not sound too impressive to the global media in the final months of 2020 (CNBC, 2020; Reuters, 2020a, 2020b). The Chinese government approved the public use of the Sinopharm and Sinovac Covid-19 vaccine, respectively, on December 31, 2020, and February 6, 2021 (Reuters, 2021a). The WHO only approved the Sinopharm and Sinovac Covid-19 vaccine for emergency use, respectively, on May 7 and June 1, 2021 (World Health Organization, 2021e, 2021g). As of June 2021, China's daily Covid-19 vaccine administration reached an impressive number of 20 million (Mallapaty, 2021).

The Russian and Chinese Covid-19 vaccines have brought a significant property into the free market following the principle of innovation management: more choices. In the partnership of COVAX, on May 27, 2021, UNICEF announced a long-term agreement regarding Sputnik V vaccine supply, with the access of 220 million doses in 2021 (UNICEF, 2021). In February 2021, China also planned to provide 10 million vaccines to the COVAX initiative (Reuters, 2021b). More varieties of good innovative products are most welcome as the world, especially low- and middle-income countries, has been facing Covid-19 vaccine shortage and distribution inequality.

As Covid-19 vaccination programs have been rolled out to quickly achieve herd immunity in many high-income countries, the progress in other regions of the world is still insufficient. The OECD realized this inequity and inefficiency in the global effort to save lives and gain back control; thus, their new policy on vaccine access aims for international distribution with long-term strategies for sharing intellectual property and technology transfer facilitation (OECD, 2021). With a globally open platform for knowledge of Covid-19 vaccine development, such as WHO's Covid-19 Technology Access Pool (C-TAP) (World Health Organization) and vaccine technology transfer hub (World Health Organization, 2021c), low- and middle-income countries can accelerate their vaccine making processes. Unlike simply repeating existing procedures, by applying the $3 \mathrm{D}$ approach of creativity to valuable insights from former projects, such inputs become the stepping-stone for further innovation. The results will be "vaccines become available where needed most" and effectively prevent or resolve local problems (e.g., logistics issues in specific areas or potential future mutation variants).

Around the world, at this time (December 2021), more than 100 Covid-19 vaccine candidates are currently going through clinical trials. It is worth mentioning that China has authorized seven homegrown Covid-19 vaccines for public use (GAVI). As an example of the innovation acceleration, while Vietnam is still facing obstacles in COVID-19 vaccination due to financial constraints, open science and global cooperation have helped increase their capacity related to vaccine development and production. In June 2021, the Vietnam Ministry of Health proposed joining the Covid-19 vaccine technology transfer program of COVAX, offering a domestic vaccine factory for the global supply (Le, 2021). Additionally, Vietnam's homegrown Covid-19 vaccine named Nano-Covax was announced on June 11, 2021, to enter clinical trials phase 3 (Vietnam Ministry of Health, 2021).

\section{Critical lessons for further improvements and efficiency of vaccination programs}

Within a year since the first data of the SARS-CoV-2 genome sequence was shared on January 10, 2020, several vaccines were developed and authorized by at least five countries. If we considered global cooperation an "international organization", Covid-19 vaccine creation would be a collective-scale innovation. This innovation resulted from a consecutive process to absorb, filter, evaluate, connect, and compare information suggested by the $3 \mathrm{D}$ creativity management framework. The process did not stop even when the innovation (e.g., vaccines) was born because the fight against Covid-19 still has a long way to go.

Humans need to continue conducting not one but many more creativity-making processes to develop global herd immunity and return to normalcy. One of the first steps is to develop modified vaccines to protect against vaccine-resistant variants (Krause et al., 2021). The SARS-CoV-2 virus does not stand still and waits for us to develop active immunity. Rather, they mutate into other variants that can be more transmissible and virulent, posing risks even for people who were previously infected or vaccinated (a.k.a. breakthrough infections) (Abu-Raddad et al., 2021; Kustin et al., 2021), such as the B.1.1.7 (or alpha), the B.1.135 (or beta), the P.1 (or gamma), and B.1.617.2 (or delta). For starting the creative process of making modified vaccines that help protect against viral variants, increasing information input (e.g., variants' genome sequence, the efficacy of existing vaccines on variants, trials' results of new vaccines, etc.) is crucial.

Acquiring vaccines does not necessarily mean that herd immunity will be achieved. Besides the challenges from viral variants, governments also face a high level of reluctance to take a vaccine among their populations. Despite being the first country to register a Covid-19 vaccine and producing vaccines with around $91 \%$ efficacy, Russia has struggled to persuade its population to be vaccinated (Chistikova and Elbaum, 2021). By June 27,2021 , only $14.81 \%$ of the Russian population had been vaccinated at least once, $\sim 10 \%$ lower than the world's record 
(23.10\%) (Mathieu et al., 2021). Other examples of vaccine reluctance are the US-a country with the fastest rise in the Covid-19 vaccine stockpile (Whitehurst and Willingham, 2021), and Israel-a country with the highest number of vaccines relative to its population (as of June 27, 2021) (Mathieu et al., 2021). Both have been experiencing high levels of vaccine reluctance among their populations. While the vaccination rates in the US fall off quickly during June 2021 (Diamond et al., 2021; Whitehurst and Willingham, 2021), Israel's percentage of people receiving at least one dose of Covid-19 vaccine only grew slowly from $54.04 \%$ (February 27, 2021) to $64.14 \%$ (June 27, 2021) after four months (Mathieu et al., 2021).

Such vaccine hesitance issues raise the demand for another creativity process to increase vaccine acceptance among populations around the globe. The outcome does not seem to be much affected by vaccines' effectiveness in this process. The public willingness to be vaccinated was mostly unchanged after a public announcement that the vaccines were 95\% effective (Kaplan and Milstein, 2021). Vaccine hesitancy is more likely to be predicted by socio-cultural and political factors (Dror et al., 2020; Hornsey et al., 2020; Kaplan and Milstein, 2021; Robertson et al., 2021; Wilson and Wiysonge, 2020). For this reason, the knowledge management process for vaccine hesitancy reduction goal requires interdisciplinary strategies to absorb and filter information. On the one hand, knowledge from social sciences plays a pivotal role in positively changing human behaviors (McCullough Chavis, 2011; Rosenfield, 1992; Van Bavel, Baicker et al., 2020; Vuong et al., 2018, 2020; Vuong and Napier, 2015) and suggesting evidence-based policymaking (Mervis, 2017; Vuong and Tran, 2019), especially regarding health communication (Van Bavel et al., 2020). Many scientists have suggested that sociocultural and institutional aspects are strong predictors of citizens' compliance with and endorsement of public health policies (Huynh, 2020; Van Bavel et al., 2020). On the other hand, combating misinformation, disinformation, fake news, conspiracy theories, and the anti-vax movement is essential for improving willingness to be vaccinated (Schwarzinger and Luchini, 2021). More specifically, attaining more insights about the perceptions, behaviors, activities, and narratives that facilitate the circulation of false information (e.g., conspiracy theories, misinformation, etc.) will support prevention efforts against the anti-vaccination infodemic and improve public communication effectiveness of scientific insights (Chan et al., 2021; Germani and BillerAndorno, 2021).

The third creativity management process that began after successfully creating Covid-19 vaccines is how to make Covid-19 vaccines distributed equally. Since some Covid-19 vaccines were authorized for emergency use, the unequal distribution of vaccines has emerged internationally (Sawal et al., 2021). More specifically, of 832 million vaccine doses administered, 82\% was distributed to high- or upper-middle-income countries, whereas low-income countries only received $0.2 \%$ of the total (United Nations, 2021). The unequal distribution might result in vast disparities in health and economic well-being (Katz et al., 2021). There are several reasons behind the unequal distribution. The high cost and technical requirements of delivering vaccines and transferring vaccine technology are some of them (Katz et al., 2021; Sawal et al., 2021; Vuong, 2018). To reduce such costs, besides continuing to innovate vaccines to be more affordable and easier to stockpile (e.g., one-dose vaccines), vaccines have to be allocated more efficiently with the right supply for the real demand. Therefore, sufficient information regarding the real situations among countries and prices of vaccines worldwide is required for global distributors, like COVAX, to deliver vaccines equitably to low- and middle-income countries.
For effectively and efficiently processing information within the creativity management (3D) processes mentioned above, the WHO has to keep the "discipline of the system". Regulatory convergence and interdisciplinary-coordinated policy responses are key factors in keeping the global corporation operating smoothly for developing Covid-19 vaccines. Their roles are again needed in developing modified vaccines for viral variants, improving vaccination rates, and equitably allocating vaccines. The virus is mutating, so we need to monitor the current situation closely and prepare against future risks proactively (Vuong, 2019).

Received: 11 July 2021; Accepted: 6 January 2022; Published online: 18 January 2022

\section{References}

Abu-Raddad LJ, Chemaitelly H, Butt AA (2021) Effectiveness of the BNT162b2 Covid-19 vaccine against the B. 1.1.7 and B.1.351 variants. N Engl J Med 383:2603-2615.

Al Jazeera (2020) Sputnik V: what we know about Russia's coronavirus vaccine https://www.aljazeera.com/news/2020/9/8/sputnik-v-what-we-know-aboutrussias-coronavirus-vaccine.

Amaro S (2021) Vaccines will be the 'most important' economic policy this year, IMF chief says. CNBC. https://www.cnbc.com/2021/06/16/covid-imf-chiefsays-vaccine-policy-is-the-most-important-economic-driver.html.

Bagdasarian N, Cross G, Fisher D (2020) Rapid publications risk the integrity of science in the era of COVID-19. BMC Med 18(1):1-5.

Balakrishnan VS (2020) The arrival of Sputnik V. Lancet Infect Dis 20(10):1128 https://doi.org/10.1016/S1473-3099(20)30709-X.

Bauchner H, Fontanarosa PB, Golub RMJJ (2020) Editorial evaluation and peer review during a pandemic: how journals maintain standards. JAMA 324(5):453-454.

Bauchner H, Fontanarosa PB, Flanagin A, Thornton J (2018) Scientific misconduct and medical journals. JAMA 320(19):1985-1987.

BioNtech. Project Lightspeed. https://biontech.de/covid-19-portal/projectlightspeed.

Caretaker (2020) Australia's first 'virtual hospital' for COVID-19 patients use Caretaker Medical wireless patient monitor for remote monitoring and reporting. Caretaker Medical. https://caretakermedical.net/australias-firstvirtual-hospital-for-covid-19-patients-use-caretaker-medical-wirelesspatient-monitor-for-remote-monitoring-and-reporting/.

CEPI (2020) CEPI establishes global network of laboratories to centralise assessment of COVID-19 vaccine candidates. https://cepi.net/news_cepi/cepiestablishes-global-network-of-laboratories-to-centralise-assessment-of-covid19-vaccine-candidates/.

Chan H-W, Chiu CP-Y, Zuo S, Wang X, Liu L, Hong Y-Y (2021) Not-sostraightforward links between believing in COVID-19-related conspiracy theories and engaging in disease-preventive behaviours. Humanit Soc Sci Commun 8(1):1-10.

Chistikova T, Elbaum R (2021). Russia registered the first Covid vaccine. Now it's struggling to vaccinate its population. NBC News. https://www.nbcnews.com/ news/world/russia-registered-first-covid-vaccine-now-it-s-strugglingvaccinate-n1272092.

CNBC (2020) Brazil institute says vaccine from China's Sinovac has efficacy above 50\%, but delays full results again. CNBC. https://www.cnbc.com/2020/12/24/ brazil-institute-says-coronavac-efficacy-above-50percent-but-delays-fullresults.html.

CORD-19 (2020) COVID-19 open research dataset. https:// www.semanticscholar.org/cord19?utm_campaign $=$ CORD19\&utm_source=hs_email\&utm_medium =email\&utm_con tent $=85059182 \& \_$hsenc $=$p2ANqtz-

_AzPEfvedG_BmLwzXX7INzZ88WRx2bF75yj1q7eG4VbJ1RjtQFBfC0z4JvHJo31krm8BKQjkx0WlPI2R2blZ-GyO2MCQ\&_hsmi=85059182.

Dang LNV, Napier NK, Hoang VQ (2013) Entrepreneurship and creativity in transition turmoil: the case of Vietnam. In: Ribiere V \& Worasinchai L (eds.), Proceedings of the International Conference on Management, Leadership and Governance-ICMLG 2013.

Diamond D, Keating D, Moody C (2021) Vaccination rates fall off, imperiling Biden's July 4 goal. The Washington Post. https://www.washingtonpost.com/ health/2021/06/06/vaccination-rates-decline-us/.

Douglas B (2020) Germany launches smartwatch app to monitor coronavirus spread. Reuters. https://www.reuters.com/article/us-health-coronavirus- 
germany-tech/germany-launches-smartwatch-app-to-monitor-coronavirusspread-idUSKBN21P1SS.

Dror AA, Eisenbach N, Taiber S, Morozov NG, Mizrachi M, Zigron A, Sela EJEJOE (2020) Vaccine hesitancy: the next challenge in the fight against COVID-19. Eur J Epidemiol 35(8):775-779.

DW (2021a) Fact check: how effective is the Sputnik V coronavirus vaccine? https://www.dw.com/en/is-sputnik-v-vaccine-safe/a-57219314.

DW (2021b) Putin gets his COVID jab as Russians stay away from Sputnik V. DW.COM. https://www.dw.com/en/putin-gets-his-covid-jab-as-russiansstay-away-from-sputnik-v/a-56963871.

Else H (2020) How a torrent of COVID science changed research publishing in seven charts. Nature 588:553.

Euronews (2021) Slovakia is second EU country to roll out Russia's Sputnik V COVID-19 vaccine. https://www.euronews.com/2021/06/07/slovakia-issecond-eu-country-to-roll-out-russia-s-sputnik-v-covid-19-vaccine.

Fleming N (2020) Coronavirus misinformation, and how scientists can help to fight it. Nature 583:155-156.

Forni G, Mantovani AJCD, Differentiation (2021) COVID-19 vaccines: where we stand and challenges ahead. Cell Death Differ 28(2):626-639.

France24 (2020) Brazil's Bolsonaro warns virus vaccine can turn people into 'crocodiles'. France24. https://www.france24.com/en/live-news/20201218brazil-s-bolsonaro-warns-virus-vaccine-can-turn-people-into-crocodiles.

Fraser N, Brierley L, Dey G, Polka JK, Pálfy M, Nanni F, Coates JA (2021) The evolving role of preprints in the dissemination of COVID-19 research and their impact on the science communication landscape. PLoS Biol 19(4):e3000959.

Gallotti R, Valle F, Castaldo N, Sacco P, De Domenico M (2020) Assessing the risks of 'infodemics' in response to COVID-19 epidemics. Nat Hum Behav 4(12):1285-1293. https://doi.org/10.1038/s41562-020-00994-6.

GAVI. The COVID-19 vaccine race. https://www.gavi.org/vaccineswork/covid-19vaccine-race.

Germani F, Biller-Andorno N (2021) The anti-vaccination infodemic on social media: a behavioral analysis. PLoS ONE 16(3):e0247642.

Graham BS (2020) Rapid COVID-19 vaccine development. Science 368(6494):945. https://doi.org/10.1126/science.abb8923.

Haas EJ, Angulo FJ, McLaughlin JM, Anis E, Singer SR, Khan F, Alroy-Preis S (2021) Impact and effectiveness of mRNA BNT162b2 vaccine against SARSCoV-2 infections and COVID-19 cases, hospitalisations, and deaths following a nationwide vaccination campaign in Israel: an observational study using national surveillance data. The Lancet 397(10287):1819-1829. https://doi.org/ 10.1016/S0140-6736(21)00947-8.

Hafner M, Yerushalmi E, Fays C, Dufresne E, Van Stolk C (2020) COVID-19 and the cost of vaccine nationalism. https://www.rand.org/pubs/research_reports/ RRA769-1.html

Haroon S (2020) Coronavirus: anti-vaxxers seek to discredit Pfizer's vaccine. The Guardian. https://www.theguardian.com/world/2020/nov/10/coronavirusanti-vaxxers-seek-to-discredit-pfizers-vaccine.

Horbach SP (2020) Pandemic publishing: medical journals strongly speed up their publication process for COVID-19. Quant Sci Stud 1(3):1056-1067.

Hornsey MJ, Finlayson M, Chatwood G, Begeny CT (2020) Donald Trump and vaccination: the effect of political identity, conspiracist ideation and presidential tweets on vaccine hesitancy. J Exp Soc Psychol 88:103947.

Hotez P, Batista C, Ergonul O, Figueroa JP, Gilbert S, Gursel M,... Bottazzi ME (2021) Correcting COVID-19 vaccine misinformation: Lancet Commission on COVID-19 Vaccines and Therapeutics Task Force Members*. EClinicalMedicine 33. https://doi.org/10.1016/j.eclinm.2021.100780.

Hu B, Guo H, Zhou P, Shi Z-L (2021) Characteristics of SARS-CoV-2 and COVID19. Nat Rev Microbiol 19(3):141-154. https://doi.org/10.1038/s41579-02000459-7.

Huynh TLD (2020) Does culture matter social distancing under the COVID-19 pandemic? Saf Sci 130:104872.

Islam MS, Sarkar T, Khan SH, Mostofa Kamal A-H, Hasan SMM, Kabir A, Seale H (2020) COVID-19?Related Infodemic and Its Impact on Public Health: A Global Social Media Analysis. Am J Trop Med Hyg 103(4):1621-1629. https://doi.org/10.4269/ajtmh.20-0812.

Jeffrey M (2020) Trump has shown little respect for U.S. science. So why are some parts thriving? Science https://www.sciencemag.org/news/2020/10/trumphas-shown-little-respect-us-science-so-why-are-some-parts-thriving.

Jocelyn S-M (2020) How did we develop a COVID-19 vaccine so quickly? Med News Today. https://www.medicalnewstoday.com/articles/how-did-wedevelop-a-covid-19-vaccine-so-quickly.

Jones I, Roy P (2021) Sputnik V COVID-19 vaccine candidate appears safe and effective. The Lancet 397(10275):642-643. https://doi.org/10.1016/S01406736(21)00191-4.

Kaplan RM, Milstein A (2021) Influence of a COVID-19 vaccine's effectiveness and safety profile on vaccination acceptance. Proc Natl Acad Sci USA 118(10):e2021726118.

Katz IT, Weintraub R, Bekker L-G, Brandt AM (2021) From vaccine nationalism to vaccine equity-finding a path forward. N Engl J Med 384(14):1281-1283.
Khatter A, Naughton M, Dambha-Miller H, Redmond P (2021) Is rapid scientific publication also high quality? Bibliometric analysis of highly disseminated COVID-19 research papers. Learned Publishing.

Krause PR, Fleming TR, Longini IM, Peto R, Briand S, Heymann DL... Ropero A-M (2021). SARS-CoV-2 variants and vaccines. $N$ Engl J Med 385:179-186.

Kumar A, Bernasconi V, Manak M, Aranha APDA, Kristiansen PA (2021) The CEPI centralised laboratory network: supporting COVID-19 vaccine development. The Lancet 397(10290):2148-2149. https://doi.org/10.1016/S01406736(21)00982-X

Kustin T, Harel N, Finkel U, Perchik S, Harari S, Tahor M,... Dror SK (2021) Evidence for increased breakthrough rates of SARS-CoV-2 variants of concern in BNT162b2-mRNA-vaccinated individuals. Nat Med 27:1379-1384.

Kwon D (2020) How swamped preprint servers are blocking bad coronavirus research. Nature 581(7807):130-132.

La V-P, Pham T-H, Ho M-T, Nguyen M-H, P Nguyen K-L, Vuong T-T, Vuong Q-H (2020) Policy response, social media and science journalism for the sustainability of the public health system amid the COVID-19 outbreak: The Vietnam lessons. Sustainability 12(7):2931.

Lancet (2020) Reviving the US CDC. The Lancet 395(10236):1521. https://doi.org/ 10.1016/S0140-6736(20)31140-5.

Le N (2021) Vietnam offers to build Covid vaccine production factory for global supply. https:/e.vnexpress.net/news/news/vietnam-offers-to-build-covidvaccine-production-factory-for-global-supply-4287262.html.

Ledford H, Van Noorden R (2020) High-profile coronavirus retractions raise concerns about data oversight. Nature 582(7811):160-161.

Ledford H, Cyranoski D, Noorden RV (2020) The UK has approved a COVID vaccine-here's what scientists now want to know. Nature 588(7837):205-206. https://doi.org/10.1038/d41586-020-03441-8.

Logunov DY, Dolzhikova IV, Zubkova OV, Tukhvatullin AI, Shcheblyakov DV Dzharullaeva AS, Grousova DM, Erokhova AS, Kovyrshina AV, Botikov AG (2020) Safety and immunogenicity of an rAd26 and rAd5 vector-based heterologous prime-boost COVID-19 vaccine in two formulations: two open, non-randomised phase 1/2 studies from Russia. Lancet 396(10255):887-897. https://doi.org/10.1016/S0140-6736(20)31866-3.

Logunov DY, Dolzhikova IV, Shcheblyakov DV, Tukhvatulin AI, Zubkova, OV, Dzharullaeva AS, Kovyrshina AV, Lubenets NL, Grousova DM, Erokhova AS, et al. (2021) Safety and efficacy of an rAd26 and rAd5 vector-based heterologous prime-boost COVID-19 vaccine: an interim analysis of a randomised controlled phase 3 trial in Russia. Lancet 397(10275):671-681. https://doi.org/10.1016/S0140-6736(21)00234-8.

MacLeod M (2020). New Normal: are virtual doctor's appointments here to stay? CTV News. https://www.ctvnews.ca/health/coronavirus/new-normal-arevirtual-doctor-s-appointments-here-to-stay-1.4939255.

Majumder MS, Mandl KD (2020) Early in the epidemic: impact of preprints on global discourse about COVID-19 transmissibility. Lancet Global Health 8(5):e627-e630.

Mallapaty S (2021) China is vaccinating a staggering 20 million people a day Nature. https://doi.org/10.1038/d41586-021-01545-3.

Martins RS, Cheema DA, Sohail MR (2020) The pandemic of publications: are we sacrificing quality for quantity? Mayo Clin Proc 95(10):2288-2290.

Mathieu E, Ritchie H, Ortiz-Ospina E, Roser M, Hasell J, Appel C,... Rodés-Guirao L (2021) A global database of COVID-19 vaccinations. Nat Hum Behav 5:947-953.

Maxmen A (2021) Why did the world's pandemic warning system fail when COVID hit? Nature 589(7843):499-500.

McCormick J, Shah A (2020) Hospitals monitor some coronavirus patients at home. World Street J. https://www.wsj.com/articles/hospitals-monitor-somecoronavirus-patients-at-home-11586856604

McCullough Chavis A (2011) Social learning theory and behavioral therapy: considering human behaviors within the social and cultural context of individuals and families. Soc Work Public Health 26(5):471-481. https:// doi.org/10.1080/19371918.2011.591629.

Mehra MR, Desai SS, Ruschitzka F, Patel AN (2020) RETRACTED: Hydroxychloroquine or chloroquine with or without a macrolide for treatment of COVID-19: a multinational registry analysis. The Lancet 395(10240):P1820.

Mehra MR, Desai SS, Kuy S, Henry TD, Patel AN (2020) RETRACTED: cardiovascular disease, drug therapy, and mortality in Covid-19. N Engl J Med 382(25):e102.

Mervis J (2017) Panel urges steps to boost evidence-based policy. Science 357(6355):959. https://doi.org/10.1126/science.357.6355.959.

Mulligan MJ, Lyke KE, Kitchin N, Absalon J, Gurtman A, Lockhart S, Neuzil K Raabe V, Bailey R, Swanson KA (2020) Phase I/II study of COVID-19 RNA vaccine BNT162b1 in adults. Nature 586:589-593. https://doi.org/10.1038/ s41586-020-2639-4.

Napier NK, Vuong QH (2013) Serendipity as a strategic advantage? In: Wilkinson T \& Kannan VR (eds.) Strategic Management in the 21st Century (Vol. 1). Santa Barbara, California: Praeger. 
National Institutes of Health (2020) Testimony on operation warp speed: researching, manufacturing, \& distributing a safe \& effective coronavirus vaccine. https://www.nih.gov/about-nih/who-we-are/nih-director/testimonyoperation-warp-speed-researching-manufacturing-distributing-safe-effectivecoronavirus-vaccine.

National Institutes of Health. Accelerating COVID-19 Therapeutic Interventions and Vaccines (ACTIV). https://www.nih.gov/research-training/medicalresearch-initiatives/activ.

National Institutes of Health. COVID-19 Clinical Research. https:// www.niaid.nih.gov/diseases-conditions/covid-19-clinical-research.

Nature (2020) Why nature needs to cover politics now more than ever. Nature 586:169-170. https://doi.org/10.1038/d41586-020-02797-1.

Nguyen M-H, Le T-T, Nguyen TH-K, Ho M-T, Nguyen TTH, Vuong Q-H (2021) Alice in Suicideland: Exploring the suicidal ideation mechanism through the sense of connectedness and help-seeking behaviors. International Journal of Environmental Research and Public Health 18(7):3681.

OECD (2021) Access to COVID-19 vaccines: global approaches in a global crisis. https://www.oecd.org/coronavirus/policy-responses/access-to-covid-19vaccines-global-approaches-in-a-global-crisis-c6a18370/.

Open COVID Pledge (2020) Make the pledge to share your intellectual property in the fight against COVID-19. https://opencovidpledge.org/.

Organization WH (2020) COVID 19 Public Health Emergency of International Concern (PHEIC). Global research and innovation forum: towards a research roadmap.

Pannett R, Cherney M (2020) Australia's coronavirus evacuation plan: a tiny island 1,000 miles away. World Street J. https://www.wsj.com/articles/ australias-coronavirus-evacuation-plan-a-tiny-island-1-000-miles-away11580295354.

Pfizer (2020a) Breakthrough vaccine to potentially protect against the spread of COVID-19. https://cdn.pfizer.com/pfizercom/2020-11/Scaling-Up\%20to\% 20Manufacture.\%20a\%20Potential\%20COVID-19\%20Vaccine.pdf.

Pfizer (2020b) Pfizer and BioNTech announce further details on collaboration to accelerate global COVID-19 vaccine development. https://www.pfizer.com/ news/press-release/press-release-detail/pfizer-and-biontech-announcefurther-details-collaboration.

Polack FP, Thomas SJ, Kitchin N, Absalon J, Gurtman A, Lockhart S, Perez JL, Pérez Marc G, Moreira ED, Zerbini C, et al. (2020) Safety and Efficacy of the BNT162b2 mRNA Covid-19 Vaccine. N Engl J Med 383:2603-2615. https:// doi.org/10.1056/NEJMoa2034577.

Retraction Watch (2021) Retracted coronavirus (COVID-19) papers. https:// retractionwatch.com/retracted-coronavirus-covid-19-papers/.

Reuters (2020a) Sinopharm's COVID-19 vaccine 79\% effective, seeks approval in China | Reuters. https://www.reuters.com/article/health-coronavirus-chinavaccine-int-idUSKBN2940CA.

Reuters (2020b) Sinovac's COVID-19 vaccine induces quick immune response study. Reuters. https://www.reuters.com/article/uk-health-coronavirussinovac-idUKKBN27X35I.

Reuters (2021a) China approves Sinovac Biotech COVID-19 vaccine for general public use. Reuters. https://www.reuters.com/article/us-health-coronavirusvaccine-sinovac-idUSKBN2A60AY.

Reuters (2021b) China to provide 10 million vaccine doses to COVAX initiative. Reuters. https://www.reuters.com/article/us-health-coronavirus-vaccinechina-idUSKBN2A30VZ

Reuters. Russia: the latest coronavirus counts, charts and maps. https:// graphics.reuters.com/world-coronavirus-tracker-and-maps/countries-andterritories/russia/.

Robertson E, Reeve KS, Niedzwiedz CL, Moore J, Blake M, Green M, immunity (2021) Predictors of COVID-19 vaccine hesitancy in the UK household longitudinal study. Brain Behav Immun 94:41-50.

Roozenbeek J, Schneider CR, Dryhurst S, Kerr J, Freeman AL, Recchia G, Van Der Linden S (2020) Susceptibility to misinformation about COVID-19 around the world. R Soc Open Scie 7(10):201199.

Rosenfield PL (1992) The potential of transdisciplinary research for sustaining and extending linkages between the health and social sciences. Soc Sci Med 35(11):1343-1357. https://doi.org/10.1016/0277-9536(92)90038-R

Samantha D (2020) Singapore's coronavirus temperature scans and tracking leading the way. The News Daily. https://thenewdaily.com.au/news/national/ 2020/03/19/singapore-coronavirus-temperature-scans/.

Sandmann FG, Davies NG, Vassall A, Edmunds WJ, Jit M, Sun FY, Klepac P (2021) The potential health and economic value of SARS-CoV-2 vaccination alongside physical distancing in the UK: a transmission model-based future scenario analysis and economic evaluation. The Lancet Infect Dis 21(7):962-974. https://doi.org/10.1016/S1473-3099(21)00079-7.

Satariano A, Alba D (2020) Burning cell towers, out of baseless fear they spread the virus. N Y Times. https://www.nytimes.com/2020/04/10/technology/ coronavirus-5g-uk.html.

Sawal I, Ahmad S, Tariq W, Tahir MJ, Essar MY, Ahmed A (2021) Unequal distribution of COVID-19 vaccine: a looming crisis. J Med Virol.
Schell D, Wang M, Huynh TLD (2020) This time is indeed different: a study on global market reactions to public health crisis. J Behav Exp Financ 27:100349. https://doi.org/10.1016/j.jbef.2020.100349.

Schwarzinger M, Luchini S (2021) Addressing COVID-19 vaccine hesitancy: is official communication the key? The Lancet Public Health 6(6):e353-e354.

Shu Y, McCauley J (2017) GISAID: global initiative on sharing all influenza data-from vision to reality. Eurosurveillance 22(13):30494.

Smith D (2020) Coronavirus: medical experts denounce Trump's theory of 'disinfectant injection'. The Guardian. https://www.theguardian.com/world/ 2020/apr/23/trump-coronavirus-treatment-disinfectant.

Stankiewicz K (2020) Bill Gates: Vaccine conspiracies targeting Dr. Fauci and me are 'unfortunate' and hurt public trust. CNBC. https://www.cnbc.com/2020/ 10/14/bill-gates-anti-vaxxer-theories-about-fauci-and-me-hurt-publictrust.html.

Taylor L (2021) 'We are being ignored': Brazil's researchers blame anti-science government for devastating COVID surge. Nature 593(7857):15-16.

Tollefson J (2020) How Trump damaged science-and why it could take decades to recover. Nature 586(7828):190-194.

U.S. Department of Defense (2020) Trump Administration announces framework and leadership for 'Operation Warp Speed' https://www.defense.gov/ Newsroom/Releases/Release/Article/2310750/trump-administrationannounces-framework-and-leadership-for-operation-warp-speed/.

U.S. Department of Defense. Coronavirus: Operation Warp Speed. https:// www.defense.gov/Explore/Spotlight/Coronavirus/Operation-Warp-Speed/.

U.S. Food \& Drug Administration (2021) Pfizer-BioNTech COVID-19 vaccine FDA. https://www.fda.gov/emergency-preparedness-and-response/ coronavirus-disease-2019-covid-19/pfizer-biontech-covid-19-vaccine.

U.S. Government Accountability Office (2021) Operation warp speed accelerated COVID-19 vaccine development status and efforts to address manufacturing challenges. https://www.gao.gov/assets/gao-21-319.pdf.

Ullah I, Khan KS, Tahir MJ, Ahmed A, Harapan H (2021) Myths and conspiracy theories on vaccines and COVID-19: Potential effect on global vaccine refusals. Vacunas 22(2):93-97. https://doi.org/10.1016/j.vacun.2021.01.001.

UNICEF (2021) UNICEF signs supply agreement for Sputnik V COVID-19 vaccine. https://www.unicef.org/press-releases/unicef-signs-supply-agreementsputnik-v-covid-19-vaccine.

United Nations (2021) Unequal vaccine distribution self-defeating. World Health Organization chief tells Economic and Social Council's special ministerial meeting.

Van Bavel JJ, Cichocka A, Capraro V, Sjåstad H, Nezlek JB, Alfano M... Boggio PS (2020) National identity predicts public health support during a global pandemic. Nature Communications In Press.

Van Bavel JJ, Baicker K, Boggio PS, Capraro V, Cichocka A, Cikara M, Druckman JN (2020) Using social and behavioural science to support COVID-19 pandemic response. Nat Hum Behav 4(5):460-471.

Velásquez N, Leahy R, Restrepo NJ, Lupu Y, Sear R, Gabriel N, Johnson NF (2021) Online hate network spreads malicious COVID-19 content outside the control of individual social media platforms. Sci Rep 11(1):11549. https:// doi.org/10.1038/s41598-021-89467-y.

Vietnam Ministry of Health (2021) Việt Nam thử nghiệm giai doạn 3 vắc xin phòng COVID-19 Nano Covax trên diện rộng. https://moh.gov.vn/tin-noibat/-/asset_publisher/3Yst7YhbkA5j/content/viet-nam-thu-nghiem-giai-oan3-vac-xin-phong-covid-19-nano-covax-tren-dien-rong.

Vuong QH (2016b) Impacts of geographical locations and socio-cultural traits on the Vietnamese entrepreneurship. SpringerPlus 5(1):1189.

Vuong QH, Napier NK (2013) Anatomy of the 3D innovation production with the Cobb-Douglas specification. Sociol Study 3(1):69-78.

Vuong QH, Napier NK (2014) Making creativity: the value of multiple filters in the innovation process. Int J Transit Innov Syst 3(4):294-327.

Vuong Q-H (2018) The (ir) rational consideration of the cost of science in transition economies. Nat Hum Behav 2(1):5.

Vuong Q-H (2019) Breaking barriers in publishing demands a proactive attitude. Nat Hum Behav 3(10):1034-1034

Vuong Q-H (2020) Reform retractions to make them more transparent. Nature 582:149. https://doi.org/10.1038/d41586-020-01694-x.

Vuong Q-H, Napier NK (2015) Acculturation and global mindsponge: an emerging market perspective. Int J Intercult Relat 49:354-367.

Vuong Q-H, Bui Q-K, La V-P, Vuong T-T, Nguyen V-HT, Ho M-T, Ho M-T (2018) Cultural additivity: behavioural insights from the interaction of Confucianism, Buddhism and Taoism in folktales. Palgrave Commun 4(1):143. https://doi.org/10.1057/s41599-018-0189-2.

Vuong Q-H, Ho M-T, Nguyen H-KT, Vuong T-T, Tran T, Hoang K-L, La V-P (2020) On how religions could accidentally incite lies and violence: folktales as a cultural transmitter. Palgrave Commun 6(1):82. https://doi.org/10.1057/ s41599-020-0442-3.

Vuong Q-H (2016a) Global mindset as the integration of emerging socio-cultural values through mindsponge processes: a transition economy perspective. In Kuada J (ed) Global Mindsets. Routledge, pp. 123-140. 
Vuong Q-H (2017) Open data, open review and open dialogue in making social sciences plausible. Sci Data Updates. http://blogs.nature.com/scientificdata/ 2017/12/12/authors-corner-open-data-open-review-and-open-dialogue-inmaking-social-sciences-plausible/.

Vuong QH, Nguyen MH, Le TT (2021) A mindsponge-based investigation into the psycho-religious mechanism behind suicide attacks. Warsaw, Poland: De Gruyter.

Vuong Q-H, Tran T (2019) The Vietnamese social sciences at a fork in the road. Walter de Gruyter GmbH \& Co KG.

Wellcome (2020) Sharing research data and findings relevant to the novel coronavirus (COVID-19) outbreak. https://wellcome.org/coronavirus-covid-19/open-data.

Whitehurst L, Willingham L (2021) US vaccine surplus grows by the day as expiration dates loom. AP News. https://apnews.com/article/joe-bidencoronavirus-pandemic-coronavirus-vaccine-health9f6d21a33db8784ea94c3edd305b0d18.

Whitelaw S, Mamas MA, Topol E, Van Spall HGC (2020) Applications of digital technology in COVID-19 pandemic planning and response. Lancet Digit Health 2(8):e435-e440. https://doi.org/10.1016/S2589$7500(20) 30142-4$.

WHO (2020a) An ad hoc WHO technical consultation managing the COVID-19 infodemic: call for action, 7-8 April 2020.

WHO (2020b) Coronavirus disease (COVID-19): Solidarity Trial and hydroxychloroquine https://www.who.int/news-room/q-a-detail/coronavirus-diseasecovid-19-hydroxychloroquine.

WHO (2021) Social media \& COVID-19: A global study of digital crisis interaction among Gen Z and Millennials. https://www.who.int/news-room/featurestories/detail/social-media-covid-19-a-global-study-of-digital-crisisinteraction-among-gen-z-and-millennials.

WHO (n.d.) Let's flatten the infodemic curve. https://www.who.int/news-room/ spotlight/let-s-flatten-the-infodemic-curve.

Wilson SL, Wiysonge C (2020) Social media and vaccine hesitancy. BMJ Global Health 5(10):e004206.

Wolfe D, Dale D (2020) 'It's going to disappear': A timeline of Trump's claims that Covid-19 will vanish. CNN. https://edition.cnn.com/interactive/2020/10/ politics/covid-disappearing-trump-comment-tracker/.

World Health Organization (2021a) ACT now, ACT together 2020-2021 Impact Report. https://www.who.int/publications/m/item/act-now-act-together2020-2021-impact-report.

World Health Organization (2021b) COVID-19 vaccine tracker and landscape. https://www.who.int/publications/m/item/draft-landscape-of-covid-19candidate-vaccines.

World Health Organization (2021c) Establishment of a COVID-19 mRNA vaccine technology transfer hub to scale up global manufacturing. https:// www.who.int/news-room/articles-detail/establishment-of-a-covid-19-mrnavaccine-technology-transfer-hub-to-scale-up-global-manufacturing.

World Health Organization (2021d) Status of COVID-19 Vaccines within WHO EUL/PQ evaluation process. In.

World Health Organization (2021e) WHO lists additional COVID-19 vaccine for emergency use and issues interim policy recommendations. https:// www.who.int/news/item/07-05-2021-who-lists-additional-covid-19-vaccinefor-emergency-use-and-issues-interim-policy-recommendations.

World Health Organization (2021f) WHO supporting South African consortium to establish first COVID mRNA vaccine technology transfer hub. https:// www.who.int/news/item/21-06-2021-who-supporting-south-africanconsortium-to-establish-first-covid-mrna-vaccine-technology-transfer-hub.

World Health Organization (2021g) WHO validates Sinovac COVID-19 vaccine for emergency use and issues interim policy recommendations. https://www.who.int/news/item/01-06-2021-who-validates-sinovaccovid-19-vaccine-for-emergency-use-and-issues-interim-policyrecommendations.

World Health Organization. COVID-19 technology access pool. https:// www.who.int/initiatives/covid-19-technology-access-pool.
World Health Organization. Emergency use listing. https://www.who.int/teams/ regulation-prequalification/eul/.

World Health Organization. The Access to COVID-19 Tools (ACT) Accelerator. https://www.who.int/initiatives/act-accelerator.

Wu JT, Leung K, Leung GM (2020) Nowcasting and forecasting the potential domestic and international spread of the $2019-\mathrm{nCoV}$ outbreak originating in Wuhan, China: a modelling study. The Lancet 395(10225):689-697. https:// doi.org/10.1016/S0140-6736(20)30260-9.

Zastrow M (2020) Open science takes on the coronavirus pandemic. Nature 581(7806):109-111.

Zhou P, Yang X-L, Wang X-G, Hu B, Zhang L, Zhang W, Shi Z-L (2020) A pneumonia outbreak associated with a new coronavirus of probable bat origin. Nature 579(7798):270-273. https://doi.org/10.1038/s41586-020-2012-7.

Zhu N, Zhang D, Wang W, Li X, Yang B, Song J, Tan W (2020) A Novel Coronavirus from Patients with Pneumonia in China, 2019. N Engl J Med 382(8):727-733. https://doi.org/10.1056/NEJMoa2001017.

\section{Author contributions}

Conceptualization: Q-HV; Methodology: M-HN, T-TL, V-PL; Formal analysis and investigation: M-HN, T-TL, V-PL; Writing-original draft preparation: M-HN, TTL, V-PL, HTTN; Writing-review and editing: M-HN, T-TL, HTTN, M-TH, QVK; Validation: Q-HV, M-HN, QVK; Resources: M-HN, T-TL, V-PL; Supervision: Q-HV.

\section{Competing interests}

The authors declare no competing interests.

\section{Ethical approval}

The study was granted exemption from requiring ethics approval, because it is a review article about knowledge management and production processes.

\section{Informed consent}

Informed consent is not available for this type of study.

\section{Additional information}

Correspondence and requests for materials should be addressed to Quan-Hoang Vuong or Minh-Hoang Nguyen.

Reprints and permission information is available at http://www.nature.com/reprints

Publisher's note Springer Nature remains neutral with regard to jurisdictional claims in published maps and institutional affiliations.

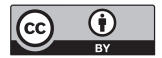

Open Access This article is licensed under a Creative Commons Attribution 4.0 International License, which permits use, sharing, adaptation, distribution and reproduction in any medium or format, as long as you give appropriate credit to the original author(s) and the source, provide a link to the Creative Commons license, and indicate if changes were made. The images or other third party material in this article are included in the article's Creative Commons license, unles indicated otherwise in a credit line to the material. If material is not included in the article's Creative Commons license and your intended use is not permitted by statutory regulation or exceeds the permitted use, you will need to obtain permission directly from the copyright holder. To view a copy of this license, visit http://creativecommons.org/ licenses/by/4.0/

(C) The Author(s) 2022 